extracted from the Statistical Review for England and Wales, 1968 (Registrar General, 1970): the mortality in children between 1 month and 5 years of age is about $1: 1,000$ while in our group of children who had a hypsarrhythmic E.E.G. the figure is about $1: 4$.

According to educational psychologists, an accepted figure for children of school age with an I.Q. above 70 is about $97 \%$, while in our series only $23 \%$ of the surviving patients achieved this level. If we then consider $3 \%$ as an accepted figure for mentally subnormal children in the general population, the figure in our series is of the order of $77 \%$. These findings therefore suggest that the presence of a hypsarrhythmic E.E.G. in the first year of life, irrespective of the clinical symptomatology at the time and largely irrespective of therapy, carries grave prognostic implications in terms of incidence of mental subnormality and early death. Since not all infants with a severe neurological illness in the first year of life develop hypsarrhythmia in their E.E.G., it is tempting to suggest that the presence of hypsarrhythmia might indicate a special type, or group, of disorders as yet unidentified.

This work was partly supported by a grant from the ClarissaNorman Research Fund on Epilepsy and by the Joint Research
Board (Hospital for Sick Children and Institute of Child Health), both gratefully acknowledged.

\section{References}

Burnett, L. L., Gibbs, E. L., and Gibbs, F. A. (1958). Pediatrics, 21, 719. Chevrie, J.-J., Aicardi, J., St. Thieffry, S., Grison, D., and Missoffe, C. (1968). Archives francaises de pédiatrie, 25, 263

Gastaut, H., Roger, J., Soulayrol, R., and Pinsard, N. (1964). L'encéphalopathie myoclonique infantile avec hypsarhythmie. Paris, Masson.

Gibbs, F. A., and Gibbs, E. L. (1952). Atlas of Electroencephalography, vol. 2. Cambridge, Mass., Addison-Wesley.

Gibbs, F. A., Gibbs, E. L., and Fleming, M. M. (1954). Pediatrics, 13, 66 Hess, R., and Neuhaus, T. (1952). Archiv für Psychiatrie und Nervenkrankheiten, vereinigt mit Zeitschrift für die gesamte Neurologie und Psychiatrie, $189,37$.

Jeavons, P. M., and Bower, B. D. (1964). In Clinics in Developmental Medicine, No. 15.

Jeavons, P. M., Harper, J. R., and Bower, B. D. (1970). Developmental Medicine and Child Neurology, 12, 413.

Lombroso, C. T., and Rose, A. (1964). Electroencephalography and Clinical Neurophysiology, 17, 464.

Pampiglione, G. (1956). Proceedings of the Electro-physiologists Technologists Association, 7, 20

Rebufat-Deschamps, M. (1958). Thesis quoted by Jeavons and Bower (1964).

Registrar General (1970). Statistical Review for England and Wales, 1968. London, H.M.S.O

Samson-Dollfus, D. (1959). Electroencephalography and Clinical Neurophysiology, 11, 578 .

Sorel, L., and Dusaucy-Bauloye, A. (1958). Acta neurologica et psychiatrica Belgica, 58, 130 .

\title{
Diagnosis of Established Deep Vein Thrombosis with the 125I Fibrinogen Uptake Test
}

\author{
N. L. BROWSE, W. F. CLAPHAM, \\ J. OLWEN WILLIAMS \\ D. N. CROFT, \\ D. J. JONES, M. LEA THOMAS,
}

British Medical fournal, 1971, 4, 325-328

\section{Summary}

One hundred and two patients with clinical signs indicating a possible diagnosis of deep vein thrombosis were studied with the fibrinogen uptake test and phlebography to assess the reliability of the test as a means of diagnosing established venous thrombosis. The test gave a correct diagnosis in $\mathbf{7 8} \%$ of the 85 legs shown to contain thrombus by phlebography and only $19(10 \%)$ falsenegative results in the 195 legs examined. The duration of the symptoms, the administration of anticoagulants, and mild leg swelling did not affect the accuracy of the test. Very old thrombus, phlebographically more than 11 days old, was associated with an increased falsenegative rate.

The fibrinogen uptake test is accurate enough to make it a valuable method of clinical investigation.

\section{Introduction}

Radioactive fibrinogen will be incorporated into a thrombus if it is circulating in the blood stream at the time that the thrombus

St. Thomas's Hospital, London S.E.1

N. L. BROWSE, M.D., F.R.c.s., Assistant Director, Surgical Unit

W. F. CLAPHAM, B.SC., Hospital Physicist

D. N. CROFT, D.M., M.R.C.P., Consultant Physician

D. J. JONES, M.B., B.S., M.R.C.P., Medical Registrar

M. LEA THOMAS, M.R.C.P., F.F.R., Consultant Radiologist

J. OLWEN WILLIAMS, M.B., B.S., M.R.C.P., Medical Registrar

forms. The thrombus will then have a high concentration of radioactivity which can be detected by external scintillation counting. This method for detecting deep vein thrombosis was first suggested by Hobbs and Davies (1960) on the basis of experiments in the rabbit. Their work was not followed up with any enthusiasm until Atkins and Hawkins (1965), Nanson et al. (1965), Flanc et al. (1968), and Negus et al. (1968) simplified the method by using the longer-lasting isotope of iodine, ${ }^{125} \mathrm{I}$, in place of ${ }^{131} \mathrm{I}$, and proved its reliability in patients after surgical operations by comparing it with phlebography.

We have been more interested in the value of the ${ }^{125} \mathrm{I}$ fibrinogen uptake test as a means of diagnosing established deep leg vein thrombosis. Some of the workers already referred to mentioned the use of the test for this purpose but did not investigate this aspect in depth (see Discussion). We present our clinical experience with 102 patients who presented with symptoms or signs of either leg vein thrombosis or pulmonary embolism. Both the fibrinogen uptake test and ascending lower limb phlebography were performed in all patients. The results show that radioactive fibrinogen does accumulate in and around well-established thrombus to a degree that makes the technique a useful diagnostic method.

\section{Patients and Methods}

Each patient examined in this study was subjected to the investigation at the request of the clinician supervising his care because there was reason to think that the patient had a deep vein thrombosis or a pulmonary embolus. The patients had either some form of symptoms in the legs (pain, tenderness, Homans's sign, swelling of the ankle, dilated veins, or increased 
temperature of the limb) or an episode of pleuritic chest pain, sudden circulatory collapse, or mild right heart failure.

${ }^{125}$ I-Fibrinogen Uptake Test.-Each patient was given $90 \mathrm{mg}$ of potassium iodide orally on the day before the test was performed, or if the request was an urgent one at the same time as the labelled fibrinogen. This dose was repeated daily for three weeks. Approximately $1 \mathrm{mg}$ of fibrinogen labelled with $100 \mu \mathrm{Ci}$ of ${ }^{125} \mathrm{I}$ was injected intravenously (Radio-chemical Centre, Amersham). The legs were then examined with a scintillation counter ( $1 \frac{1}{4}$ in $(3.2 \mathrm{~cm})$ sodium iodide crystal) 18 to 28 hours later by the method described by Negus et al. (1968). Points at 4 -in $(10-\mathrm{cm})$ intervals below the inguinal ligament were examined with a 3 -in $(7.5 \mathrm{~cm})$ diameter collimator which viewed an area 4 in $(10 \mathrm{~cm})$ in diameter at a depth of $1 \frac{1}{2}$ in $(3.8 \mathrm{~cm})$. The maximum count over the heart was recorded and the counts in the legs were expressed as a percentage of the heart count. In half the patients the count rate was measured with a ratemeter, in the other half it was recorded with a timer and scaler. The ratemeter was used with a time-constant setting of 3 seconds and the scaler/timer with a counting time of 10 seconds for each point. For the activity used the count rates obtained were generally such that errors due to counting statistics were small. The results from a few cases where very low count rates occurred were discarded. Differences due to positioning of the counter in the absence of an abnormality were also found to be small.

Phlebography.-All patients had their peripheral veins examined by phlebography. The technique which has been previously described (Browse et al., 1967) displays the major deep veins of the calf, the popliteal veins, the superficial femoral vein, the mouth of the profunda vein, the iliac veins, and the vena cava. Whenever possible both legs were examined but for clinical reasons this was not always done, hence the total number of legs studied is an odd number.

Objects of the Trial.-There were three main objects of the trial: (1) to discover if the ${ }^{125} \mathrm{I}$-fibrinogen uptake test was an accurate diagnostic method for established thrombosis, (2) to decide the best criteria for making the diagnosis, and (3) to compare the two methods of examination, one using a ratemeter and the other a scaler and timer. Two criteria for a positive test were examined: $(a)$ if the difference between readings (expressed as a percentage of the heart count) at adjacent points, or the equivalent point on the opposite leg, was more than $15(1 \times$ $15 \%)$, and $(b)$ if there were three adjacent points each greater by 5 than the same three points on the other leg (this cannot detect symmetrical bilateral thrombosis) $(3 \times 5 \%)$.

\section{Results}

The ages of the 102 patients (45 women and 57 men) ranged from 19 to 79 (average 52 years); the average age of the women was 49 and of the men 52. Most were medical patients but many postoperative and postpartum patients are included. The underlying diseases are not presented in detail as this is not particularly relevant to the study.

Seventeen of the patients had only the signs of pulmonary embolism, 44 had only the signs of deep vein thrombosis, and 41 had symptoms of both. Physical signs or symptoms were found in the left leg in 29 patients, in the right leg in 27, and in both legs in 29 . Thus $85(82 \%)$ had some physical signs in the legs to suggest the diagnosis of deep vein thrombosis.

The duration of the symptoms varied-in 24 patients it was of less than 5 days' duration, in 23 it was of 6-10 days' duration, and in 35 it was more than 10 days. There was no way of assessing the age of the thrombosis in 20 .

Patients with local conditions in the legs likely to cause falsepositive readings, such as infection, ulceration, haematoma, bruising, or flesh wounds, were excluded from the test. Swelling of the leg was not considered a contraindication unless it was gross.

Sixty-four of the 102 patients were on anticoagulants-19 were on heparin alone, 27 had been on warfarin for five days or less, and 18 had been on warfarin for more than five days.

\section{DIAGNOSTIC ACCURACY}

Effect of Apparatus Used for Counting.-The correlation between phlebography and the fibrinogen uptake test in the 50 patients who were examined with the scintillation counter and a ratemeter and in the other 52 patients examined with the scaler and timer is shown in Table I. With either the $1 \times 15 \%$ or $3 \times 5 \%$ criterion (see definitions above) there was no difference between the results obtained. Therefore subsequent analyses were based on all 102 patients and the method of instrumentation was ignored. TABLE I-Comparison of Correlation between Fibrinogen Uptake Test (F.U.T.)
and Phlebogram with Two Different Types of Instrumentation (Scaler and Timer, and Ratemeter)

\begin{tabular}{|c|c|c|c|c|}
\hline Instrumentation & Criteria & $\begin{array}{l}\text { Agreement } \\
\text { of } \\
\text { Phlebogram } \\
\text { and F.U.T. }\end{array}$ & $\begin{array}{c}\text { Negative } \\
\text { Phlebogram, } \\
\text { Positive } \\
\text { F.U.T. }\end{array}$ & $\begin{array}{c}\text { Positive } \\
\text { Phlebogram, } \\
\text { Negative } \\
\text { F.U.T. }\end{array}$ \\
\hline 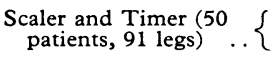 & $\begin{array}{l}1 \times 15 \% \\
3 \times 5 \%\end{array}$ & $\begin{array}{l}70(77 \%) \\
70(77 \%)\end{array}$ & $\begin{array}{l}9(10 \%) \\
3(3 \%)\end{array}$ & $\begin{array}{l}12(13 \%) \\
18(20 \%)\end{array}$ \\
\hline $\begin{array}{c}\text { Ratemeter } \\
104 \text { legs) }\end{array}$ & $\begin{array}{l}1 \times 15 \% \\
3 \times 5 \%\end{array}$ & $\begin{array}{l}70(77 \%) \\
84(81 \%)\end{array}$ & $\begin{array}{l}10(10 \%) \\
13(12 \%)\end{array}$ & $\begin{aligned} & 14(13 \%) \\
& 7(7 \%)\end{aligned}$ \\
\hline
\end{tabular}

Reliability of Diagnostic Criteria.-The analysis of all patients, comparing the $1 \times 15 \%$ with the $3 \times 5 \%$ criteria, is shown in Table II. The agreement between phlebogram and fibrinogen uptake test and the numbers of false-positive and false-negative tests are almost identical. The agreement was so good that we decided to accept either or both criteria as a positive test. On this basis there was agreement between the phlebogram and the test in $80 \%$ (Table II). Of the 156 legs in which there was agreement between the two methods of diagnosis, 46 had

TABLE II-Overall Correlation between Fibrinogen Uptake Test and Phlebography using Three Criteria for Positive F.U.T. (102 Patients, 195 Legs)

\begin{tabular}{|c|c|c|c|}
\hline Criteria & Agreement & $\begin{array}{c}\text { False-Positive } \\
\text { F.U.T. }\end{array}$ & $\begin{array}{c}\text { False-Negative } \\
\text { F.U.T. }\end{array}$ \\
\hline $\begin{array}{l}1 \times 15 \% \\
3 \times 5 \% \\
\text { Either } 1 \times 15 \% \text { or } \\
\quad 3 \times 5 \% \text {, or both }\end{array}$ & $\begin{array}{l}150(77 \%) \\
153(79 \%)\end{array}$ & $\begin{array}{l}19(10 \%) \\
16(8 \%)\end{array}$ & $\begin{array}{l}26(13 \%) \\
26(13 \%)\end{array}$ \\
\hline
\end{tabular}

thrombus demonstrated by phlebography and 110 did not. It is very likely that the "false-positive" fibrinogen uptake tests are in fact true positives-that is, these are cases in which the thrombus was small and hidden within the muscle and so not detected by the phlebogram. The test was positive in 66 of the $85(78 \%)$ legs that contained thrombus. If it is accepted that a positive fibrinogen uptake test is a true positive the falsenegative rate in legs known to contain thrombus was $22 \%$. Considering all legs, whether with or without thrombus on the phlebogram, the false-negative test rate was $10 \%$, giving an overall diagnostic accuracy of $90 \%$. It must be stressed that a true-negative result is just as important in clinical practice as a true-positive result.

Timing of the Examination.-The results so far described were derived from a single examination done between 18 and 28 hours after injecting the fibrinogen. A number of patients were studied on subsequent days, particularly when their test was positive, to see if the result of the test altered. Sixty-two were examined on three occasions over a five-day period. The agreement between phlebography and the test at the first test 
was $75 \%$, at the second it was $77 \%$, and at the third test it was $71 \%$. Forty-six legs were examined at 24 and 48 hours. There were three false-positive fibrinogen uptake tests one of which became negative on the second day, the others did not change. There were 11 false-negative tests, five of which became positive on the second day. Thus a second measurement at 48-50 hours increased the number of true-positive results, but the overall improvement was not great. Examination at 6 or 12 hours sometimes gave an accurate result but it did not seem to be reliable enough for clinical purposes.

\section{EFFECT OF CLINICAL FACTORS ON ACCURACY OF TEST}

Only results from patients with a definite thrombosis-that is, those with a positive phlebogram or a positive test-have been analyzed for this section. Probably the only incorrect results are the false negatives.

Duration of Leg Symptoms and Signs.-It is not possible to be certain of the true age of a deep vein thrombus because it can exist for days without causing symptoms or signs. Most patients had leg symptoms or signs, and the accuracy of the test was analyzed with respect to their duration (Table III), on the assumption that the duration of the symptoms is related to the age of the thrombus and is certainly not greater than its true age. As can be seen from Table III there is no obvious correlaTABLE III-Correlation between Fibrinogen Uptake Test and Phlebography in
Relation to Duration of Symptoms and Signs in 79 Legs and Effective Anticoagulation in 47 Legs

\begin{tabular}{|c|c|c|c|}
\hline & Agreement & $\begin{array}{c}\text { False-Positive } \\
\text { F.U.T. }\end{array}$ & $\begin{array}{c}\text { False-Negative } \\
\text { F.U.T. }\end{array}$ \\
\hline $\begin{array}{l}\text { Duration of Leg } \\
\text { Symptoms and Signs: } \\
0-5 \text { days } \ldots\end{array}$ & $\begin{array}{r}13(59 \%) \\
11(48 \%) \\
19(56 \%) \\
7(50 \%) \\
14(61 \%) \\
4(40 \%)\end{array}$ & $\begin{array}{r}5(23 \%) \\
3(13 \%) \\
10(29 \%)\end{array}$ & $\begin{array}{l}4(18 \%) \\
9(39 \%) \\
5(15 \%)\end{array}$ \\
\hline
\end{tabular}

tion between the diagnostic accuracy of the fibrinogen uptake test and the duration of symptoms and signs in the legs.

Anticoagulant Drugs.- It might be expected that the fibrinogen uptake test would be negative in the presence of adequate anticoagulation. Table III shows the effect of the administration of anticoagulants on the accuracy of the test. Heparin was usually given in divided doses, 40,000 units $/ 24$ hours. All the patients on warfarin were adequately treated by our standard-that is, a prothrombin index $\geqslant 1.8$. It can be seen that the accuracy of the test was unaffected by the administration of heparin or less than five days of warfarin. After five days of warfarin there was a high level of false negatives but the number of legs in this group is rather small. The duration of treatment is, of course, related to the age of the thrombus. Age when studied alone did not seem to have any effect, but Table III implies that the thrombosis treated with warfarin for more than 10 days is likely to be missed by the test. Whether this is solely due to the warfarin or to a combination of age of the thrombus and anticoagulants is not clear. The important practical interpretation of Table III is that anticoagulants need not be withheld while waiting for the test to be performed.

Oedema and Inflammatory Lesions in the Leg.-At the onset of this trial it was found that gross leg oedema could give rise to a false-positive fibrinogen uptake test, perhaps because the radioactive fibrinogen leaked into the oedema fluid. We have other unpublished evidence that ${ }^{125} \mathrm{I}$-fibrinogen leaks into lymphoedema. Thus we excluded patients with gross leg oedema from this study. Lesser degrees of leg swelling did not appreciably affect the reliability of the test. There was $78 \%$ agreement between the test and phlebography in those legs (18) with mild swelling of the calf and thigh and a $75 \%$ agreement in those legs (28) with swelling of the ankles only, which compares favourably with an overall agreement of $80 \%$ (Table II). Superficial inflammatory lesions were also found in preliminary studies to cause a false-positive test. Thus it is important to examine the legs, and to exclude any patient with superficial thrombophlebitis, varicose ulceration, sepsis, haematuria, flesh wounds, or active arthritis.

\section{ANALYSIS OF DISAGREEMENTS}

Positive Test, Negative Phlebogram.-Twenty legs gave a positive fibrinogen uptake test but no thrombus was seen on the phlebogram. As has been mentioned before, phlebography does not always detect small thrombi in intramuscular veins. We believe that these positive tests are probably true positives. In none of these 20 legs was there a local abnormality that could have accounted for the high count rate. The duration of symptoms and signs in this group was no different from the overall distribution, and the proportion on anticoagulants did not differ significantly from the group as a whole. Thus no factors were found to cause the false-positive tests, which makes the deduction that they were true positives, a reasonable one.

Negative Test, Positive Phlebogram.-When thrombus was visible on the phlebogram 19 legs gave a negative test. The duration of clinical history was $\leqslant 5$ days in $4(21 \%), 6$ to 10 days in $9(47 \%)$, $>10$ days in $5(26 \%)$, and not known in $1(5 \%)$. These proportions differ from the figures for the group as a whole where there are more patients with a long history. The phlebograms of these 19 legs were re-examined to make a radiographic assessment of the age of the thrombus. If it had a smooth outline and was surrounded by a thin layer of contrast medium it was classed as less than 7 days old. If the thrombus was beginning to retract and had a thickened irregular margin, or was completely fixed and occluding the vein, it was classed as 7-14 days old. Irregular recanalizing thrombus in a narrowed vein was classed as more than 14 days old. These changes due to ageing have been described elsewhere (Lea Thomas and McAllister, 1971). Only three false-negative thrombi were less than 7 days old, 13 were 7-14 days old, and three were more than 14 days old. Thus a high proportion of radiologically old thrombi was in the falsenegative group, and though there seemed to be no relationship between the duration of the symptoms and the incidence of false-negative tests this objective data on the age of the thrombus does imply that a false-negative result is more common with old thrombus.

\section{Discussion}

Hobbs and Davies (1960), who first described the selective uptake of ${ }^{131} \mathrm{I}$-fibrinogen into forming thrombus, suggested that it might be used for detecting thrombosis after surgical operations. When Atkins and Hawkins (1965) described the test with ${ }^{125}$ I-fibrinogen they mentioned studies on eight patients with established deep vein thrombosis, stating that they had an increased count rate in the affected leg 24 hours after giving the labelled fibrinogen, but they gave no details. Flanc et al. (1968) described the cases of 31 patients ( 36 limbs) who had clinical evidence of deep vein thrombosis and on whom they performed the fibrinogen uptake test and phlebography. In 24 legs there was agreement between the test and the phlebogram $(66 \%)$. In six legs the test was positive and the phlebogram negative $(17 \%)$ and the same number of legs (six) showed a false-negative test. They stated that the test would be useful in 
diagnosis only when a thrombus is still forming and that once it is fully established the test would be negative.

Our studies have given better results. With the use of phlebography as the absolute method of diagnosis the test gave a correct result in $78 \%$ of the legs known to contain thrombus. When all legs were considered, and all positive tests accepted as true results, the false-negative rate was only $10 \%$. As all of these patients were thought to have established thrombosis the results show that the test is accurate enough to be of clinical value, even when the thrombus is no longer growing but showing the radiological features of ageing.

We obtained confirmation of the ability of old thrombus to take up fibrinogen when a patient, not in this series, died 48 hours after being given ${ }^{125} \mathrm{I}$-fibrinogen. Three weeks previously he had had a phlebogram which showed a thrombus in the superficial femoral vein jutting into the common femoral vein. At necropsy this thrombus was exactly the same size and shape as it had appeared on the phlebogram three weeks earlier. It showed macroscopic signs of ageing, brown discoloration, and central softening, and yet it contained four times more radioactivity than the surrounding blood. We have had similar findings in animal experiments where the thrombus had been established for seven days before giving the ${ }^{125} \mathrm{I}$-fibrinogen. These experiments also showed that the count rate from the inflamed vein wall was also higher than surrounding tissue (Browse, unpublished studies). Atkins and Hawkins (1968) also found in the dog that thrombus that was 24 hours old still selectively absorbed the labelled fibrinogen.

The likely explanation for these results is that thrombus is not an inactive substance, unaffected by changes in the blood, but that substances are selectively taken up, giving rise to a higher concentration in the thrombus than in the blood. Thrombus should therefore be considered as an active metabolizing tissue. It may be that "active" thrombus-that is, the type that is still concentrating fibrinogen-is the very type that it is clinically important to recognize, whereas old-established inactive thrombus is of less immediate importance to the patient.

The test is easy to perform and, apart from the intravenous injection, can be done by a technician. As well as ourselves, five technicians participated in this study and once the methodology was learned there was nothing to suggest any appreciable degree of observer error. The test is therefore robust in both a theoretical and a technical sense.

We performed this study using the technique and crit ria described by Negus et al. (1968), and the difference of the $1 \times$ $15 \%$ criterion that they eventually chose has correlated very well with the phlebograph. However, as many established thrombi do not take in circulating fibrinogen to such a high degree as new growing thrombi, we also decided to assess the value of a lower difference in count rate over a wider area. The $3 \times 5 \%$ criterion that we chose was found to be as accurate as the $1 \times 15 \%$. We recommend therefore that for diagnostic studies in established cases either or both criteria can be used.
In practice it is easier to look first for the $15 \%$ difference and if in doubt then use the $3 \times 5 \%$.

In this study we have taken phlebography to be the absolute method of diagnosis. However, this is certainly not true when the thrombus is small and within inaccessible muscle veins in the calf and thigh. If it is assumed that only the false-negative fibrinogen uptake tests are real mistakes then the test gives a correct diagnosis in $90 \%$ of cases.

None of our patients had any of the conditions which cause false-positive readings, such as acute arthritis, ulcers, haematomata, cellulitis, local trauma, or superficial thrombophlebitis. These conditions must be looked for before ordering the test and are a contraindication to it.

Recently there has been concern about the risk of giving the patient serum hepatitis. The fibrinogen used by the Radiochemical Centre is from donors who have been observed for two and a half years and who are Australia-antigen negative. We have not had a patient become jaundiced and have done over 400 tests. In our opinion the value of the test in the clinical diagnostic situation outweighs the risk of hepatitis.

The radiation dose to the patient's thyroid gland is small, about one-tenth of that given during a thyroid scan using ${ }^{131} \mathrm{I}$. Though we always give potassium iodine to saturate the thyroid this is probably unnecessary and can be omitted in the urgent clinical situation. We have seen no side effects from the iodine used to suppress the thyroid gland.

These studies show that the fibrinogen uptake test is an accurate method $(90 \%)$ for detecting established deep leg vein thrombosis in the veins of the middle and lower thigh and calf even when the thrombus is quite old and the patient anticoagulated. We have found it a valuable tool in the diagnosis and management of patients with venous thrombosis and embolism.

We are grateful for the technical help of Miss C. Baker, Miss G. Gollop, Miss R. Redford, and Mrs. A. Taylor. Part of this work was supported by a grant from the Medical Research Council to one of us (N.L.B.). This work could not have been performed without the support of the physicians and surgeons of St. Thomas's Hospital who referred patients for investigation.

\section{References}

Atkins, P., and Hawkins, L. A. (1965). Lancet, 2, 1216.

Atkins, P., and Hawkins, L. A. (1968). British fournal of Surgery, 55, 825 Browse, N. L., Lea Thomas, M., and Solan, M. J. (1967). British Medical Fournal, 4, 596.

Flanc, C., Kakkar, V. V., and Clarke, M. B. (1968). British fournal of Surgery, 55, 742.

Hobbs, J. T., and Davies, J. W. L. (1960). Lancet, 2, 134

Lea Thomas, M., and McAllister, V. (1971). Radiology, 99, 37.

Nanson, E., Palki, P., Dick, A., and Fedoruk, S. (1965). Annals of Surgery, 162,438 .

Negus, D., Pinto, D. J., LeQuesne, L. P., Brown, N., and Chapman, M. (1968). British fournal of Surgery, 55, 835. 